\title{
INSIGHTS FROM THE FRONT LINES: A COLLECTION OF STORIES OF HTA IMPACT FROM INAHTA MEMBER AGENCIES
}

Tara Schuller

INAHTA Secretariat c/o Institute of Health Economics INAHTA@ihe.ca

\author{
Sophie Söderholm Werkö \\ Swedish Council on Health Technology Assessment
}

This mini-theme contains six stories of health technology assessment (HTA) impact from member agencies of The International Network of Agencies for Health Technology Assessment (INAHTA), which were originally shared at the 2015 and 2016 INAHTA Congresses. The INAHTA impact story sharing is an innovative network activity where member agency representatives share experiences of HTA impact in a loosely structured story format. Through this process, members gain insights from other agencies on new ways of thinking about and approaching HTA impact assessment. A guide is provided to members to prepare their story, and the best story receives the David Hailey Award for Best Impact Story. This mini-theme contains stories of HTA impact from six member agencies in different parts of the world: the Health Assessment Division of the Ministry of Public Health (Uruguay), the Institute of Quality and Efficiency in Health Care (Germany), the Health Information and Quality Authority (Ireland), the Finnish Office for Health Technology Assessment (Finland), the Australian Safety and Efficacy Register of New Interventional Procedures-Surgical (Australia), and the Institut national d'excellence en santé et en services sociaux (Canada). Across the papers, common themes emerge about the importance of appropriate engagement of stakeholders and the broadening scope of HTA beyond reimbursement decision making.

Keywords: Technology assessment, Biomedical, Decision making, Quality Assurance, Health care, Program evaluation

A search in the International Journal of Technology Assessment in Health Care for articles containing the term "storytelling" produces zero results and a search for "story" returns three papers that are over 20 years old (1-3). The low number of papers on this topic may not come as a surprise given the technical and largely quantitative world of health technology assessment. On the face of it, storytelling is at odds with the "hard" science of health technology assessment (HTA). And yet, in 2015 the International Network of Agencies for Health Technology Assessment (INAHTA) created a story sharing activity that has quickly become an integral and valued part of the annual INAHTA Congress.

This innovative network activity involves sharing stories about HTA impact. This topic was chosen because it is an area that INAHTA members are interested to learn about and information about impact is not easy to find anywhere else. In this activity, each member agency representative shares their experiences in a loosely structured story with the freedom to touch on different elements that they see as important. The diverse stories that are shared allow members to gain insights from other agencies on new ways of thinking about and approaching HTA impact assessment.

A guideline (4) is provided to members ahead of time so they can prepare their stories for the Congress. The story shar-

The Associate Editors, Schuller \& Söderholm Werkö, thank the INAHTA members who contributed manuscripts to this mini-theme on HTA impact. ing occurs informally in small groups and allows time for questions and answers so participants gain an understanding of the circumstances described in the stories, which are often woven into complicated health system processes and involve a range of stakeholders.

INAHTA members share a common identity as publiclyfunded HTA agencies with links to regional or national health system decision makers (5). This common identity fosters trust among those involved so they feel comfortable sharing stories of what has worked well, or not so well, to achieving HTA impact. Furthermore, the small group structure of the story sharing builds bonds of friendship that are important in a large network like INAHTA where membership currently spans thirty countries and fifteen languages.

At the INAHTA Congress each year, the best story is chosen by members according to defined criteria (4) and the winner receives the David Hailey Award for Best Impact Story that is named in honor of Prof. David Hailey, a longtime champion of HTA impact research (6). In 2015, the first recipient of the award was the Health Assessment Division at the Ministry of Health in Uruguay for a story written by Aleman and Perez Galan entitled, "Impact of HTA in litigation concerning access to high-cost drugs" (7). In 2016, the award-winning story was from INESSS in Canada, entitled "Shaping quality in Québec trauma through vision and quality monitoring", authored by Truchon et al. (8).

In the spirit of shared learning, INAHTA offers this collection of HTA impact stories from the 2015 and 2016 INAHTA 
Congresses. Both of the stories that received the David Hailey Award for these years are included in this IJTAHC mini-theme, along with four others that are representative of the global diversity of INAHTA members. These INAHTA impact stories provide real-world insights about some of the tough challenges in HTA and the valuable contributions it makes to health system decision making.

In the study from the Health Assessment Division of the Ministry of Public Health in Uruguay, Aleman and Perez Galan (7) describe a unique situation of HTA impacting upon litigation concerning access to high-cost drugs. They highlight the role that HTA played in writ of protection cases and remark on the lack of knowledge of HTA processes in the judicial system. In a study from the Institute of Quality and Efficiency in Health Care (IQWiG), Fujita-Rowherder et al. (9) tell a story about an IQWiG HTA of knee arthroscopic surgery for osteoarthritis. The HTA provoked a strong response from local clinicians and one of the conclusions drawn by the authors is the importance of involving stakeholders in the HTA process in the right way and at the right time. A similar observation is made in the story from Ireland, where Ryan et al. (10) describe the vital contributions of stakeholder engagement to the impact of an HTA of automated external defibrillators conducted by the Health Information and Quality Authority (HIQA). The story tells about the role of a robust media management strategy as a crucial part of the HTA process as a means to promote public engagement and understanding of the issues.

The story from the Finnish Office for Health Technology Assessment (FinOHTA) is authored by Sihvo et al. (11) who describe levels of awareness and implementation of MUMM recommendations by secondary care physicians. Their story brings to light the role that organizational culture can have in the transfer and application of new knowledge in clinical practice. From the Australian Safety and Efficacy Register of New Interventional Procedures-Surgical (ASERNIP-S) comes a story by Tivey et al. (12) about their application of rapid review HTA methods to assess the legislative and accreditation requirements for office-based surgery in Australia. Their results show that loopholes exist where higher-risk surgeries could occur without the necessary clinical practice safeguards. The study from the Institut national d'excellence en santé et en services sociaux (INESSS) by Truchon et al. (8) describes the development of a regulated hospital triage system for quality improvement in trauma care through visioning and quality monitoring in Québec, Canada. The story is an example of the application of HTA methods to broader technology management and health system optimization.

Across these six stories a common theme emerges of the importance of appropriate stakeholder engagement to achieve positive HTA impact. Stakeholders such as patients, clinicians, and decision makers are specified, but so are other stakeholders that may not usually be associated with HTA, namely politicians, the media, lawyers, and judges. The papers in this mini-theme also exemplify the broadening scope of HTA to inform not only technology reimbursement decisions, but also to inform legislation, legal proceedings, technology management, optimization, health system organization, and service delivery.

So, you are now invited into this world of storytelling; to discover insights from the front lines of HTA impact that are shared in these narrative-style papers from INAHTA member agencies.

\section{CONFLICTS OF INTEREST}

Tara Schuller, MSc, BA, is employed as the Executive Manager of the INAHTA Secretariat. Dr. Söderholm Werkö is employed as Manager, International Relations \& Patient Engagement at The Swedish Council on Health Technology Assessment (SBU).

\section{REFERENCES}

1. Reiser S. The intensive care unit: The unfolding and ambiguities of survival therapy. Int J Technol Assess Health Care. 1992;8:382-394. doi:10.1017/S0266462300013696

2. D'Adler M. The transfer of medical information: A journalist's view. Int $J$ Technol Assess Health Care. 1988;4:59-63. doi:10.1017/S0266462300003263

3. Sheehan H. (1986). What makes medical systems Indian?: A consideration of doctor, family, and gender in India. Int J Technol Assess Health Care. 1986;2:243-252. doi:10.1017/S0266462300002051

4. INAHTA. Impact story sharing guideline. http://www.inahta.org/ hta-tools-resources/hta-impact-influence/\#Story (accessed October 15, 2017).

5. INAHTA. Membership criteria. http://www.inahta.org/about-inahta/ memberships/ (accessed October 15, 2017).

6. INAHTA. Interview with David Hailey. http://www.inahta.org/ hta-tools-resources/hta-impact-influence/\#DH (accessed September 30, 2017).

7. Aleman A, Perez Galan A. Impact of health technology assessment in litigation concerning access to high-cost drugs. Int J Technol Assess Health Care. 2017;Jul 31:1-4. doi:10.1017/S0266462317000575

8. Truchon C, Moore L, Belcaid A, et al. Shaping quality through vision, structure, and monitoring of performance and quality indicators: Impact story from the Quebec Trauma Network. Int J Technol Assess Health Care. 2017;Jun 5:1-5. doi:10.1017/S0266462317000198

9. Fujita-Rohwerder N, Rüther A, Sauerland S. Arthroscopic surgery for knee osteoarthritis: Impact of health technology assessment in Germany. Int J Technol Assess Health Care. 2017;Oct 18:1-4. doi:10.1017/S0266462317000861

10. Ryan M, Moran P, Harrington P, et al. Contribution of stakeholder engagement to the impact of a health technology assessment: An Irish case study. Int J Technol Assess Health Care. 2017;Oct 16:1-6. doi:10.1017/S026646231700085X

11. Sihvo S, Ikonen T, Mäkelä M. Implementing health technology assessment-based recommendations in Finland: Managed uptake of medical methods. Int J Technol Assess Health Care. 2017;Jul 13:1-4. doi:10.1017/S0266462317000587

12. Tivey D, Ma N, Duncan J, et al. INAHTA impact story: Legislative and accreditation requirements for office-based surgery in Australia. Int $J$ Technol Assess Health Care. [add issue, DOI, page number, etc.] 